\title{
Development of Co-simulation and Analysis by Combination of Aerodynamics, Mechanism Dynamics and Control System Dynamics for Large Wind Turbines
}

\author{
Mao-Hsiung Chiang, Ching-Sung Wang, \\ Tsung-Chih Tung, Jhih-Hong Lin \\ Department of Engineering Science \& Ocean Engineering, \\ National Taiwan University, \\ Taipei, Taiwan
}

\begin{abstract}
The objective of the paper is to develop a novel cosimulation analytic interface of aerodynamics, mechanism dynamics and control system dynamics for $2 \mathrm{MW}$ wind turbines. Therefore, three software, such as FAST, ADAMS, and MATLAB/ SIMULINK, are integrated into one interface to combine with aerodynamic, mechanism dynamic and control system dynamic simulation. The dynamic response of blades, transmission system, and other subsystems can be simulated under different input circumstances of wind. The closed-loop simulation of the pitch control and the yaw control of cabinet can both be performed. Finally, the co-simulation results of the $2 \mathrm{MW}$ wind turbine will be verified by verification, and the results shows that the co-simulation analysis of aerodynamics, mechanism dynamics and control system dynamics for $2 \mathrm{MW}$ wind turbines developed in this paper can describe the overall system characteristics satisfactorily.
\end{abstract}

Keywords-wind turbine; co-simulation; aerodynamics; yaw control; pitch control; dynamic simulation; fuzzy sliding mode control

\section{INTRODUCTION}

Wind energy has been considered one of the most important green energies being developed and applied worldwide for years, while there are some challenges that makes the turbine reduce its' efficiency. As the pitch angle of the blade is fixed, the electric power output isn't controlled so the output power is easily influenced by larger disturbance from varying wind speeds and thus has worse electric power quality. Therefore, a variable pitch control wind turbine was developed. By controlling the variable pitch angle of the blade, the rotational speed of the wind turbine can be kept constant so rated electric power can still be produced when the wind speed is higher than the rated wind speed.

Dynamic simulation of wind turbines that has become a key technology in the design procedure of wind turbine can evaluate the dynamic characteristics of wind turbine. In the recent years, some dynamic simulation software has been developed. In 2002, National Renewable Energy Laboratory (NREL) developed the simulation software FAST, which new version, V7.01.00a-bjj, was introduced in 2012. In 2006, Boukhezzar [1] cooperated with NREL and proposed Multivariable controller for torque control and pitch control. FAST was used to build a nonlinear model of wind turbine. PID and LQG control was used and compared. Zhang [2] used FAST to simulate WindPACT-1.5MW and developed

\author{
Chia-Ming Chang, Jui-Hung Liu, Jien-Chen Chen, \\ Meng-Ru Wu, Chih-Hsun Peng \\ Industrial Technology Research Institute, \\ Hsinchu, Taiwan
}

synchronize generator and multi-objectives controller by MATLAB/SIMULINK for overall system control. In 2008, Fadaeinedjad [3-4] developed a Double-Feedback Induced Generator model via MATLAB and combined with FAST. $\mathrm{Lu}$ [6] investigated the Load Computation of a $150 \mathrm{~kW}$ Wind Turbine by IEC-61400-1 via FAST/SIMULINK. In 2010, Mandic [7] proposed FAST combined with a Permanent Magnetic Synchronized Generator (PMSG) model.

ADAMS(Automatic Dynamic Analysis of Mechanical Systems) that was first developed by MDI (Mechanical Dynamics Inc.) and then transferred to MSC Ltd, called MD Adams(Multibody Dynamics Adams) has been applied widely in many industrial design and dynamic simulation of complex mechanism and multi-body system.

This paper aims to develop the co-simulation analysis of aerodynamics, mechanism dynamics and control system dynamics for $2 \mathrm{MW}$ wind turbines. Three software, such as FAST, ADAMS, and MATLAB/SIMULINK, are used for aerodynamic, mechanism dynamic and control system dynamic simulation. The dynamic response can be analyzed under different input of wind. The closed-loop simulation of subsystem can be performed. Finally, the co-simulation results are compared with a $2 \mathrm{MW}$ wind turbine for verification, and the results shows that the co-simulation analysis of aerodynamics, mechanism dynamics and control system dynamics for $2 \mathrm{MW}$ wind turbines developed in this paper can describe the overall system characteristics satisfactorily.

The paper is organized as follows. In the next section, we proposed the model that we researched in this paper, and some equations and assumptions were given. In Section 3, the simulation result based on a random unpredictable wind condition was presented to testify the response of each subsystem. Furthermore, the validity of control strategy also showed in this condition due to a wide range of input wind. Finally, we concluded our paper in section 4.

\section{The Mathematic Model of Wind Turbine System}

First, a dynamic model in FAST software, including aerodynamic forces, torque coefficient and transmission system is derived. Next, the nonlinear dynamic models of wind turbine system, containing a permanent magnet synchronous generator, a pitch control system driven by a DC motor and a yaw system driven by four AC motors using MATLAB/SIMULINK software. 
The power of winds that we can acquire from wind turbine system can be express as:

$$
P_{w}=\frac{1}{2} \rho A V_{w}^{3} C_{P}(\lambda, \beta)
$$

The loading torque and torque coefficient of the wind turbine system can be described as:

$$
\begin{gathered}
T_{w}=\frac{P_{w}}{\omega_{t}}=\frac{1}{2} \rho \pi V_{w}^{2} R^{3} C_{q}(\lambda, \beta) \\
C_{q}(\lambda, \beta)=\frac{T_{w}}{\frac{1}{2} \rho A V_{w}^{2} R}
\end{gathered}
$$

Where $\lambda$ is the tip-speed ratio; $\rho$ indicates air density; $C_{p}$ is power coefficient $C_{q}$ is torque coefficient, ' $V_{w}$ is wind speed, $A$ is the area of blade covering region, $R$ is blade length, $\beta$ is blade pitch angle and $\omega_{t}$ is turbine rotational speed. How much power we can acquire is related to the tip-speed ratio, which also affects the value of power coefficient.

\section{A. Dynamic Model of Wind Turbine}

Figure 1 shows the co-simulation mode of these four software.. By using the dynamic link library file(adams2010.dll), we can co-simulate these three software in MATLAB. Both of these two methods use AeroDyn software, located in FAST, to calculate the Lift, Drag, and Pitching moment coefficient.

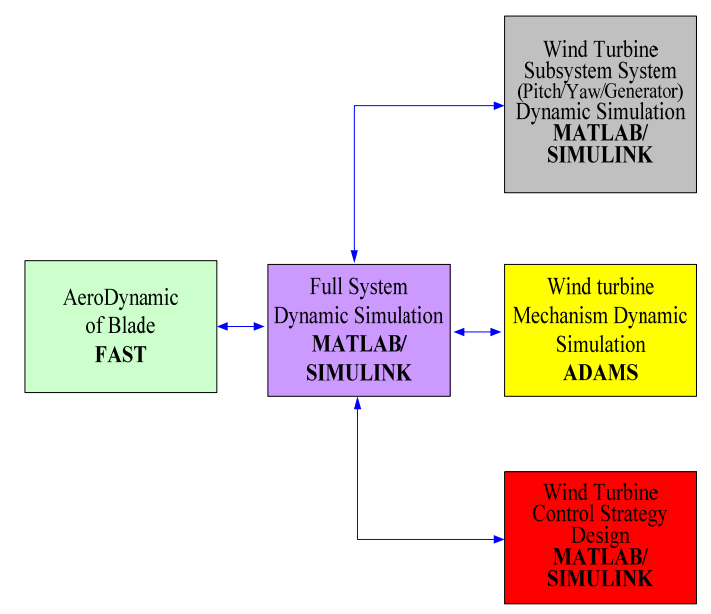

Figure 1. Co-simulation of FAST(Aerodynamics), ADAMS(Mechanism Dynamic ) and MATLAB/ SIMULINK(subsystems and control system) for wind turbines

\section{B. Subsystem Setup}

The main subsystems of wind turbine can be composed of three different components: pitch, yaw, and generator system. Pitch system is usually driven by a direct-driven DC motor since the system needs a quick response due to the high impulsive loading from the winds. A simple DC motor can be formulated as Eq (4):

$$
v_{a}=R_{a} i_{a}(t)+L_{a} \frac{d i_{a}(t)}{d t}+v_{m}(t)
$$

Where $v_{a}$ denotes voltages, $R_{a}$ is equivalent resistance, $L_{a}$ is equivalent inductor from the circuit, and $v_{m}$ is a back electromotive force voltage from the motor side. With the equivalent circuit and loading system from the blade, we can easily derived the equations and expressed them with block diagram as shown in Figure 2

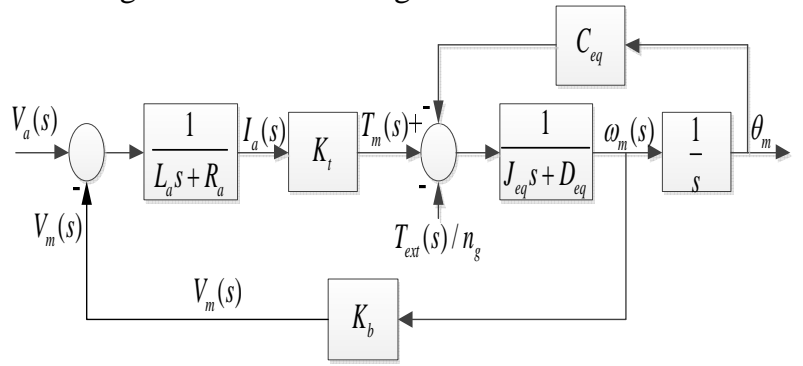

Figure 2. Block diagram of DC motor in pitch system

For a yaw system, this system was installed with four AC induction motors due to its low response when comparing with pitch system and large moment of inertia of nacelle. The basic equivalent equation of induction motor is based on [10] a theory of stator and rotor equation compensated with indirect vector control theory to decouple the coupling phenomenon from rotor. The equivalent equations can be expressed as Eq (5)-(6) :

$$
\begin{gathered}
v_{q s}=R_{i} i_{q s}+L_{i} s i_{q s}+k_{b} \omega_{m} \\
T_{e}=\frac{3}{4} p \frac{L_{m}^{2}}{L_{r}} i_{d s} i_{q s}=k_{t} i_{q s}
\end{gathered}
$$

With $v_{q s}$ and $i_{q s}$ as voltage and current of $q$ axis of the motor and $i_{d s}$ is denoted as a current from d axis. $L_{r}, L_{m}$, and $L_{i}$ represent the induction of rotor, sympathy, and electric circuits separately, while $K_{c}$ and $K_{f}$ are the compensative gain from currents.

Finally, the block diagram can be illustrated as Figure 3 to represent the induction motor mechanism. 


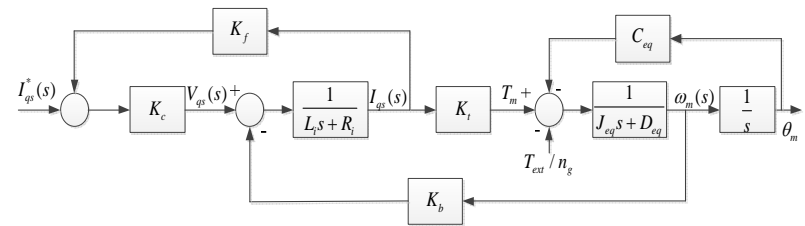

Figure 3. Block diagram of AC induction motor in yaw system

Subsequently, a generator should be setup to generate the electric power. In this case, a rotor directly loaded on the generator with equipping with a gear box-set. Therefore, a permanent magnetic synchronized generator was picked up to overcome the low speed from the drivetrain. In order to simplify the generator model, the converter and grids were neglected in this model and the characteristics were equivalent to a nonlinear, time-variant, and coupled system. The basic theories are familiar with induction motor but compensate with a "Field-orient Theory" [11] to complete the model. With the simplified equations from $\mathrm{Eq(7)-(9),}$ the system can finally calculate the electromagnetic power from the equations.

$$
\begin{gathered}
v_{d s}=R_{s} i_{d s}+\left(L_{d s}+L_{l s}\right) \frac{d i_{d s}}{d t}-\omega_{e}\left(L_{d s}+L_{l s}\right) i_{q s} \\
v_{q s}=R_{s} i_{q s}+\left(L_{d s}+L_{l s}\right) \frac{d i_{q s}}{d t}+\omega_{e}\left[\left(L_{d s}+L_{l s}\right) i_{d s}+\Psi_{P M}\right] \\
T_{e}=\frac{3}{2} p\left[\left(L_{d s}-L_{q s}\right) i_{d s} i_{q s}+\Psi_{P M} i_{q s}\right]
\end{gathered}
$$

With subtitles ds and qs are the meaning of $d$ axis and $q$ axis respectively, while $\mathrm{p}$ means othe pole pairs of the generator, and $T_{e}$ denotes the electromagnetic torque and $\Psi_{P M}$ is the magnetic flux of permanent magnet. $\omega_{e}$ is expressed as electromagnetic speed in generator.

\section{SimUlation RESUlTS AND DISCUSSION}

The wind turbine system operates at various wind conditions, which are divided into the three different regions. We generate a fluctuating wind speed from 3.5 to $20 \mathrm{~m} / \mathrm{s}$, as shown in Fig.4(a). When the wind speed reaches the third region, the pitch system driven by the DC motor starts to drive the blade to affect the blade aerodynamics to contain a nearly stable maximum power output. This strategy not only offers a nearly stable loading torque for the generator to acquire energies, but also protect the generator form exceeding the rated rotational speed (23.5 rpm). Figure 4 shows the simulation results. In Fig.4(a), we can see a wind rises from $3 \mathrm{~m} / \mathrm{s}$ to $16 \mathrm{~m} / \mathrm{s}$, then wind speed start to fluctuate in variance of $1 \mathrm{~m} / \mathrm{s}$. Figures $4(\mathrm{~b}) \sim(\mathrm{c})$ show the dynamic simulation result of each blades. Figures 4 (d) (e) are the dynamic response of the yaw system. Finally, Figures 4 (f) (g) shows the response of the generator. (a)

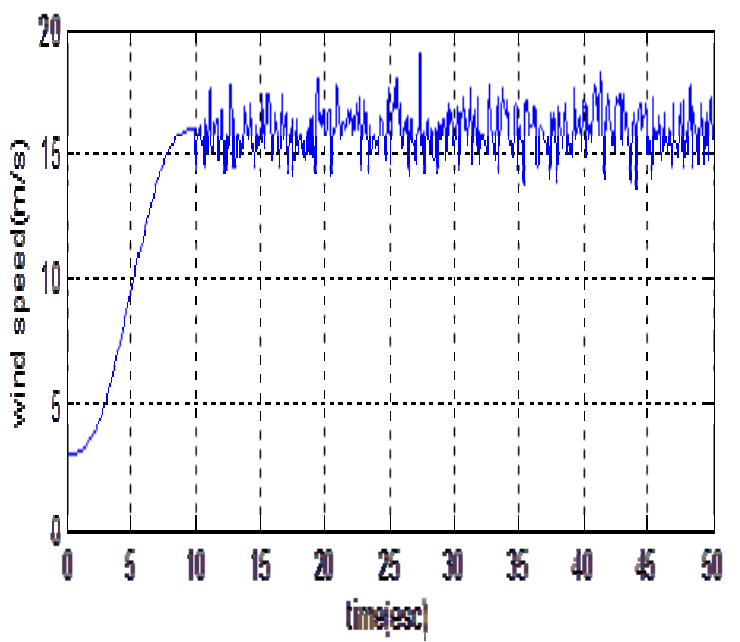

(b)

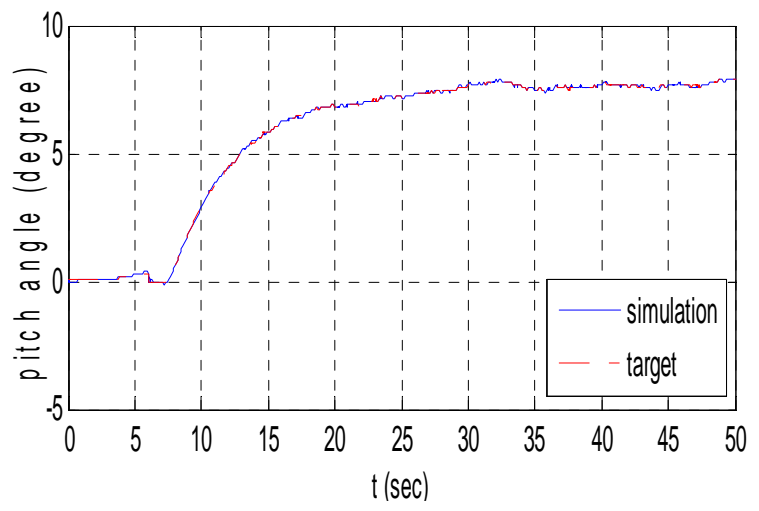

(c)

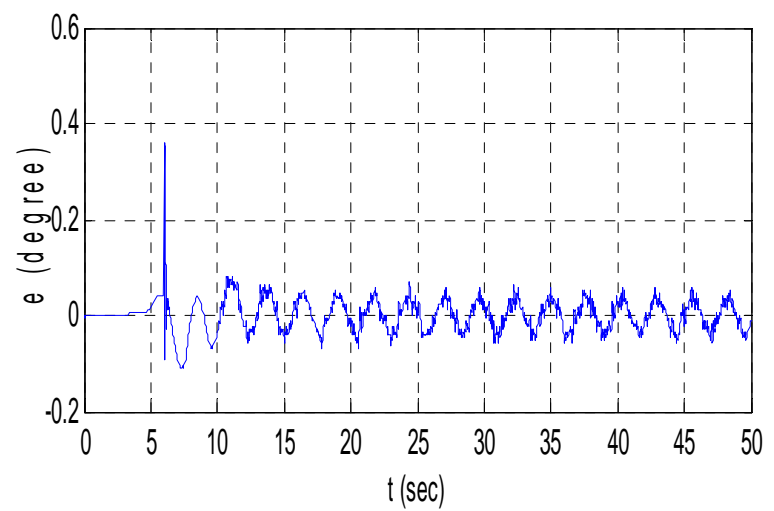

Figure 4. (a) (c): blade pitch dynamic response: (a) input wind files (b)pitch one tracking result (c) pitch one tracking error 
(d)

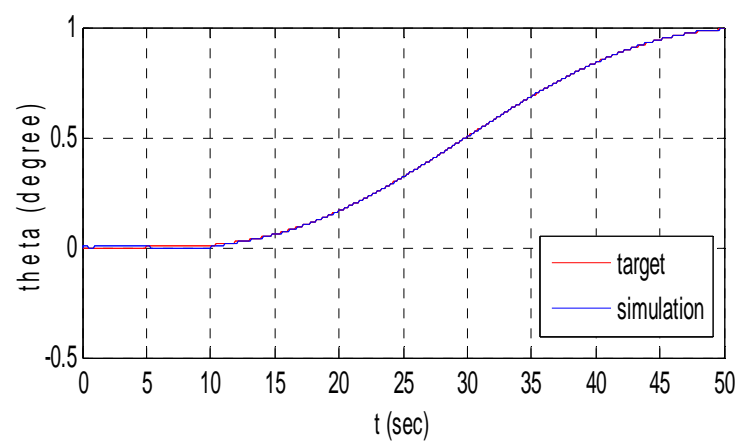

(e)

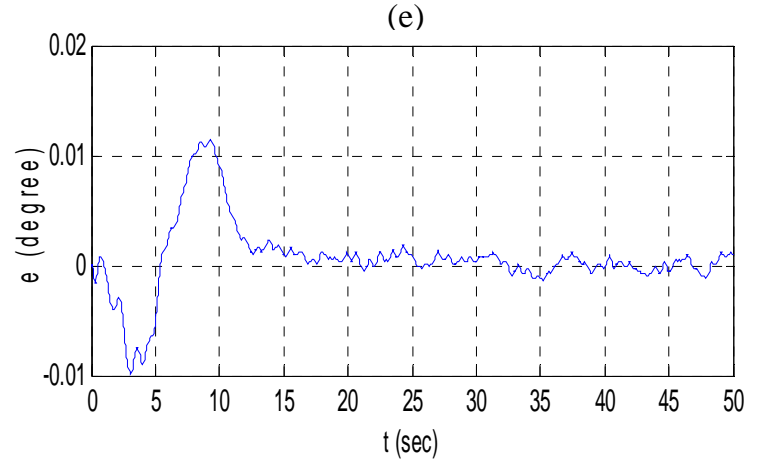

(f)

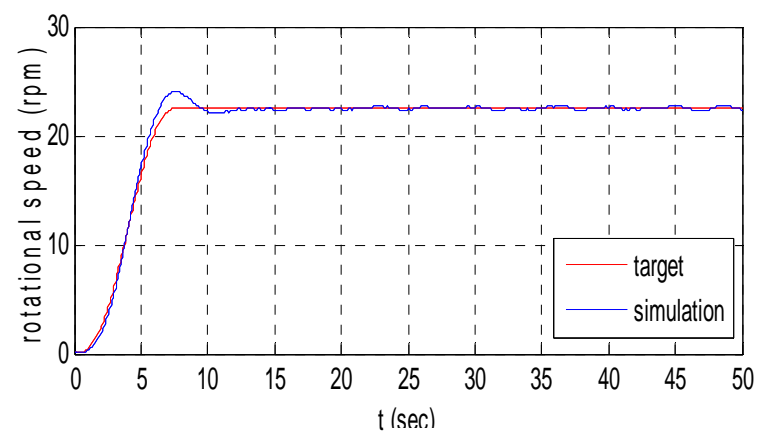

(g)

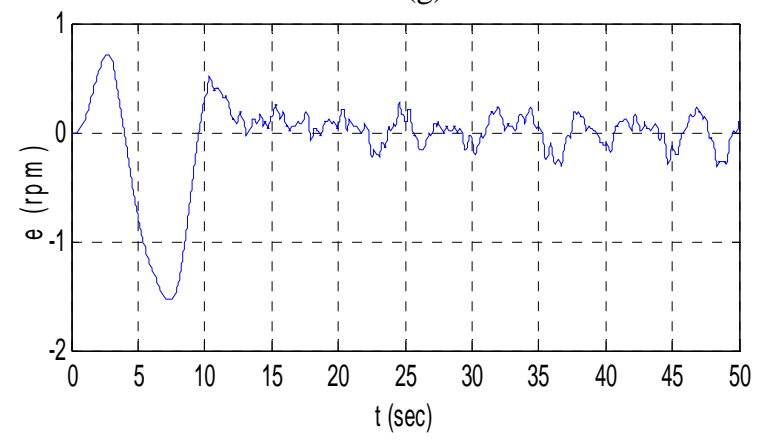

Figure 4. (d) (g): dynamic response: (d) yaw tracking result (e) yaw tracking error (f) generator speed tracking result (g) rotational speed tracking error

\section{CONCLUSIONS}

This study proposed and developed the co-simulation analysis of aerodynamics, mechanism dynamics and control system dynamics for $2 \mathrm{MW}$ wind turbines. Three software, are used for aerodynamic, mechanism dynamic and control system dynamic simulation in order to satisfy the requirement of the dynamic simulation analysis of the overall system of $2 \mathrm{MW}$ wind turbines. Finally, the cosimulation results are compared with a $2 \mathrm{MW}$ wind turbine for verification, and the results shows that the co-simulation analysis of overall system is satisfied.

\section{ACKNOWLEDGEMENT}

The financial support provided by Bureau of Energy (Grant 103-D0107) is gratefully acknowledged

\section{REFERENCES}

[1] B. Boukhezzar, L. Lupu, H. Siguerdidjane, M. Hand, "Multivariable control strategy for variable speed, variable pitch wind turbines", Renewable Energy volume 32, Issue 8, Page(s):1273-1287, July 2007.

[2] Jianzhong Zhang, Ming Cheng, Zhe Chen, "Design of Wind Turbine Controller by Using Wind Turbine Codes”, International Conference on Electrical Machines and System, 2008 (ICEMS2008), Page(s):2591-2595, Oct. 2008.

[3] R. Fadaeinedjad, G. Moschopoulos, M. Moallem, "Simulation of a Wind Turbine with Doubly-Fed Induction Machine Using FAST and Simulink”, International Symposium on Industrial Electronics (ISIE 2006), Page(s):2648-2653, July 2006.

[4] R. Fadaeinedjad, M. Moallem, G. Moschopoulos, "Simulation of a Wind Turbine with Doubly Fed Induction Generator by FAST and Simulink”, IEEE Transactions on Energy Conversion, Vol. 23, Issue 2, Page(s): 690-700, June 2008.

[5] Sayooj B Krishna, S. V. Reeba, "Simulation of Wind Turbine with Switched Reluctance Generator by FAST and Simulink", 10th National Conference on Technological Trends (NCTT09), Page(s): 106-111, Nov 2009.

[6] R.K.Lu, C.R.Chang, Load Computation of a 150kWWind Turbine by IEC-61400-1via FAST/SIMULINK”, 2009 Taiwan Wind Energy Conference,Taipei, Taiwan, Page(s): 1-6, Dec. 2009.

[7] G. Mandic, A. Nasiri, "Modeling and Simulation of a Wind Turbine System with Utlracapacitors for Short-Term Power Smoothing”, IEEE International Symposium on Industrial Electronics (ISIE 2010), Page(s): 2431-2436, July 2010.

[8] R. Fadaeinedjad, G. Moschopoulos, A. Ghareveisi, "Utilizing a STATCOM to Prevent the Flicker Propagation in a Wind Power System", IEEE Energy Conversion Congress and Exposition (ECCE 2010), Page(s):679-686, Sept. 2010.

[9] scheme applied to robot manipulator”, Int. J. Control, Vol. 45, no. 45, Page(s): 1197-1209, 1987

[10] T. F. Chang. K. L . Shi, Y. K. Wong and S. L . Ho, "Modelling and Simulation of The Three-phase Induction Motor Using Simulink," International Journal of Eletric Engineering vol. 36, pp. 163-172, 1999.

[11] Garbriele Michalke, Anca D. Hansen, Thomas Hartkopf, “Control strategy of variable speed wind turbine with multiple permanent magnet synchronous generator”, European Wind Energy Conference and Exhibition EWEC, Milano, Page(s): 1-8, May 2007. 